\title{
NON-INVASIVE VENTILATION IN A NON-STANDARD SETTING - IS IT SAFE TO VENTILATE OUTSIDE THE ICU?
}

\author{
I. Boyadzhieva', M. Kovacheva², D. Bektashev³, E. Mekov ${ }^{1}$ \\ 1'Department of Pulmonary Diseases, Medical Faculty, Medical University - Sofia, Bulgaria \\ ${ }^{2}$ Department of Gastroenterology, Medical Faculty, Medical University - Sofia, Bulgaria \\ ${ }^{3}$ Medical Faculty, Medical University - Sofia, Bulgaria
}

\begin{abstract}
Non-invasive ventilation (NIV) is considered a fundamental method in treating patients with various disorders, requiring respiratory support. Often the lack of beds in the intensive care unit (ICU) and the concomitant medical conditions, which refer patients as unsuitable for aggressive treatment in the ICU, highlight the need of NIV application in general non-monitored wards and unusual settings - most commonly emergency departments, high-dependency units, pulmonary wards, and even ambulances. Recent studies suggest faster improvement of all physiological variables, reduced intubation rates, postoperative pulmonary complications and hospital mortality with better outcome and quality of life by early well-monitored ward-based NIV compared to standard medical therapy in patients with exacerbation of a chronic obstructive pulmonary disease, after a surgical procedure or acute hypoxemic respiratory failure in hematologic malignancies. NIV is a ceiling of treatment and a comfort measure in many patients with do-not-intubate orders due to terminal illnesses. NIV is beneficial only by proper administration with appropriate monitoring and screening for early NIV failure. Successful NIV application in a ward requires a well-equipped area and adequately trained multidisciplinary team. It could be initiated not only by attending physicians, respiratory technicians, and nurses but also by medical emergency teams. Ward-based NIV is supposed to be more cost-effective than NIV in the ICU, but further investigation is required to establish the safety and efficacy in hospital wards with a low nurse to patient ratio.
\end{abstract}

Key words: non-invasive ventilation, general ward, efficacy, safety, cost-effectiveness

Corresponding author: Evgeni Mekov, MHATPD "Sveta Sofia",19, "Acad. Ivan Geshov" blvd, 1431 Sofia, Bulgaria, tel. +359 888320 476, e-mail: evgeni.mekov@gmail.com

\section{INTRODUCTION}

$\mathrm{N}$ on-invasive ventilation (NIV) is a method for respiratory support in cases of acute or chronic respiratory failure, provided with the use of a tight-fitting facial mask instead of an endotracheal or tracheostomy tube [1]. Thus, endotracheal intubation and invasive mechanical ventilation (IMV) with all of their disadvantages are avoided.
The latest guideline on NIV use was published by the European Respiratory Society and American Thoracic Society in 2017 [2]. The expert panel recommends a variety of indications for NIV, including COPD exacerbation with respiratory failure and acidosis, cardiogenic pulmonary edema, respiratory failure in immunocompromised patients, postoperative respiratory failure, palliative care, chest trauma and weaning from IMV. Regarding NIV support for asthmatic flare 
and acute hypoxemic respiratory failure, the experts do not give any recommendation, nor is there strong evidence to support it. NIV has been also used for respiratory support in neuromuscular disorders [3, 4], kyphoscoliosis [5] and obesity hypoventilation syndrome [6].

The intensive care unit (ICU) is undoubtedly the safest place to deliver any kind of respiratory support [7]. However, because of the constant shortage of ICU beds, many patients do not get the chance to receive respiratory support, even though they need it [8]. This is why there is an increasing number of studies regarding NIV use in unusual settings most commonly emergency departments, high dependency units, pulmonary or general wards, and even ambulances [9-11].

\section{INDICATIONS FOR NIV OUTSIDE OF THE ICU}

An international survey showed an increasing trend in NIV use in general non-monitored wards [12]. The treatment was described as successful in more than half the cases and most physicians did not transfer their patients to the ICU. As it has been established in other studies [13-15], the majority of respondents concluded that deterioration of gas exchange, inability to tolerate the face mask, and inability to manage secretions lead to NIV failure in most cases.

An NIV trial in the ward can be performed in many patients that are waiting for an ICU bed or are unlikely to get one. Most of them are hypercapnic or have acute pulmonary edema, but some are surgical cases with postoperative complications. In selected patients oxygenation and respiratory mechanics could be improved significantly after only a few hours of NIV, making intensive care management unnecessary. This is usually the case of acute cardiogenic pulmonary edema, presenting in the emergency department. More complex cases that need long term respiratory support and continuous supervision are best to be referred to the ICU as soon as possible. This statement is especially true for patients with acute hypoxemic respiratory failure. As NIV is not a guideline approved treatment modality for them, it should be attempted only by experienced physicians and nurses.

\section{COPD EXACERBATION}

NIV for an exacerbation of chronic obstructive pulmonary disease (COPD) with acute hypercapnic respiratory failure is the most common scenario for ventilatory support in the pulmonary or the general ward [16]. A study by Dave et al. even suggests that it is safe to ventilate patients with a $\mathrm{pH}$ of 7.6 outside of the ICU [17]. In their study, Schiavo et al. further investigated the link between acid-base balance and ward-based NIV application. They report that the coexistence of respiratory and metabolic disturbances determines an increased need for NIV and consecutive IMV [18].

The cornerstone study of non-ICU-based NIV is the YONIV trial (Yorkshire Non-Invasive Ventilation trial). It is the largest trial (236 patients) and demonstrated that the early use of NIV in addition to standard medical therapy for hypercapnic respiratory failure due to COPD exacerbation leads to a more rapid improvement of all physiological variables, reduces intubation rate and hospital mortality [19].

After the YONIV trial, evidence of the safety of ward-based NIV started to emerge [17-26] and the technique is now widely used, especially in limitedresource settings [27]. A recent observational noninferiority study by Parker et al. compared three models of NIV care for patients with COPD exacerbation: general ward with 1:4 nurse to patient ratio, thriceweekly consultant ward round, a high dependency unit with 1:2 nurse to patient ratio, twice daily ward rounds and an ICU with 1:1 nurse to patient ratio, twice daily ward rounds. In this study, the ward-based NIV model was equally effective as the high dependency and intensive care unit models [28]. It is important to note that the high nurse to patient ratio in the general ward cannot be achieved in many hospitals outside of the economically developed countries, due to staff shortage [29-31] . In this regard, further investigation is needed to establish the safety and efficacy of ward-based NIV with a low nurse to patient ratio.

The key steps for a successful ward-based NIV trial for COPD exacerbations are early recognition [25], frequent arterial blood gas monitoring in the first hours after ventilation onset [26], frequent circuit leak checks [24] and proper staff training [21]. Dres et al. found that improvement in staff training and experience leads to an increasing number of NIV-treated patients and is associated with better outcomes [21]. The nutritional status of the patients, together with the $\mathrm{PaCO}_{2}$ values, are also important factors for the successful NIV treatment in the ward [32].

\section{CARDIOGENIC PULMONARY EDEMA}

Continuous positive airway pressure (CPAP) is the mainstay of cardiogenic pulmonary edema management. Its benefits and cost-effectiveness have been well es- 
tablished over time [2]. Cardiogenic pulmonary edema has a special place in the list of respiratory emergencies because it develops and resolves quickly, which gives grounds to use NIV before ICU admission to prevent sudden deterioration in the patient's condition.

Outside the ICU, CPAP therapy for cardiogenic pulmonary edema has been used effectively in the general ward [33], in the emergency department [34] and in the pre-hospital setting [35].

\section{POSTOPERATIVE PATIENTS}

A retrospective study looked at the use of NIV in the general surgical ward [36]. The most common indications for postoperative NIV are lung infections, acute respiratory distress syndrome, and heart failure. Starting NIV in the ward could prevent ICU admission and IMV in many patients with complex problems, especially after emergency surgery. It could also be useful in patients with a poor prognosis as a ceiling of therapy. Olper et al. have also effectively used NIV in the cardiac surgery ward to treat respiratory failure [37].

NIV could be used in a surgical ward not only as a tool for managing postoperative pulmonary complications but also as a preventive measure. Lockstone et al. studied the use of physiotherapists-delivered NIV in patients who have undergone upper abdominal surgery [38]. Other studies underline the benefits of prophylactic NIV after thoracic, cardiac and abdominal surgery, but they are all exclusively ICU based and the ventilation is applied by physicians [39-45]. All research data on prophylactic postoperative NIV show a significant reduction of postoperative pulmonary complications in patients receiving NIV. More data are necessary to draw any conclusions about the safety of NIV use in the surgical ward, but the Lockstone and Olper studies give a solid base for further investigations in this area of expertise.

\section{HEMATOLOGIC MALIGNANCIES}

Patients with hematologic malignancies are profoundly immunocompromised. They are at high risk of developing nosocomial infections, especially if intubated. This is why the 2017 European Respiratory Society guideline recommends non-invasive respiratory support for acute respiratory failure in such patients. Most studies in hematologic malignancy patients are conducted in the ICU because these patients are vulnerable and require special care. One small trial in a group of patients with hematological malignancies and acute hypoxemic respiratory failure treated with NIV directly in the ward achieved favorable results in comparison to a historical cohort [46].

\section{PATIENTS WITH DO-NOT-INTUBATE AND COMFORT-MEASURES-ONLY ORDERS}

An increasing number of patients with terminal illnesses all over the world express their wish to die with dignity with do-not-intubate order. Such patients are not feasible candidates for ICU admission, but they could still benefit from respiratory support in the ward. For all of them, the NIV is a ceiling of treatment and a comfort measure, relieving dyspnea and suffering in the last days, or even months of life.

A systematic review and meta-analysis revealed that $56 \%$ of patients with do-not-intubate orders treated with acute NIV were discharged and $32 \%$ were still alive after one year. Moreover, there was no difference between the in-hospital mortality of patients that received NIV in or outside of the ICU. A general concern among terminally ill patients is the prolongation of their suffering. The results of this meta-analysis also underline that there was no decrease in the quality-of-life of survivors following acute NIV, which is beneficial in regards to palliative care [47].

Trethewey et al. noted an increasing number of COPD patients that expressed their wishes not to be intubated, being treated with NIV in the ward. These patients have taken an informed end-of-life decision for NIV to be their ceiling of treatment. The number of COPD patients with treatment limitations will grow because of deeper patient education and understanding of the nature of the illness, as well as the demand for ward-based NIV, applied by non-intensivists [48].

\section{Monitoring patients on NIV}

One of the main problems of ward-based NIV is the lack of proper monitoring. Technical resources differ among countries and even hospitals in the same country, so a standard monitoring package should be applied to all ventilated patients no matter where the intervention is being performed. Close monitoring to detect signs of patient deterioration is essential for preventing delays in ICU admission and treatment escalation [49]. A UK survey on ward-based NIV revealed that mortality was higher in patients treated with NIV than those treated with standard therapy. This data demonstrates that NIV is beneficial only if it is administered properly and adequate monitoring has been applied to screen for early NIV failure [50].

The following parameters should be monitored, while a patient is on NIV [51].

1. Clinical parameters: patient comfort; mask tolerance; respiratory rate; presence of dyspnea and signs of increased work of breathing; Glasgow Coma Scale; the capability of protecting the airway and presence of effective cough; stom- 
ach distention (aerophagia); SAPS II and/or APACHE II scores; delirium.

2. Physiological parameters: $\mathrm{SpO}_{2}$; blood gas analysis; transcutaneous $\mathrm{CO}_{2}\left(\mathrm{PtCO}_{2}\right)$; end-tidal $\mathrm{CO}_{2}$ $\left(\mathrm{EtCO}_{2}\right)$;

3. Ventilator parameters: respiratory rate; minute ventilation; presence of a large leak; flow-volume and pressure-volume curves; intrinsic PEEP; patient-ventilator synchrony;

4. Cardiac parameters: heart rate; ECG; blood pressure; echocardiography;

5. Imaging abnormalities.

The same authors suggest the following minimum monitoring sets according to the severity of respiratory failure [51]:

1. Mild ( $\mathrm{pH} 7.35-7.30$; respiratory rate < 25): optional continuous nurse monitoring; occasional blood pressure monitoring, heart rate, and respiratory rate measurement; $\mathrm{SpO}_{2}$ measurement every 2-4 h; arterial blood gas measurement every $8 \mathrm{~h}$; leak check, tidal volume, I:E ratio, and minute ventilation every $2-4 \mathrm{~h}$; occasional monitoring for a patient-ventilator asynchrony.

2. Moderate $(\mathrm{pH} 7.30-7.20$; respiratory rate $=25$ 35): continuous nurse monitoring; occasional blood pressure measurement; continuous heart rate and respiratory rate monitoring; frequent monitoring of the level of consciousness; continuous $\mathrm{SpO}_{2}$ monitoring; arterial blood gas measurement every 2-4 h; $\mathrm{PtcCO}_{2}$; leak check, tidal volume, I:E ratio, and minute ventilation every $1 \mathrm{~h}$; frequent monitoring for a patient-ventilator asynchrony; flow traces, compliance, and resistance monitoring;

3. Severe $(\mathrm{pH}<7.20$; respiratory rate $>35)$ : obligatory continuous nurse monitoring; continuous blood pressure monitoring, heart rate, and respiratory rate monitoring; frequent monitoring of the level of consciousness; continuous $\mathrm{SpO}_{2}$ monitoring; frequent arterial blood gas measurements; $\mathrm{PtcCO}_{2}$; continuous leak monitoring, tidal volume, I:E ratio, and minute ventilation; frequent monitoring for a patient-ventilator asynchrony; flow traces, compliance, and resistance monitoring.

Monitoring of patients on NIV is complex and requires high nurse to patient ratio that cannot be provided in many general wards. This is why an NIV trial should be considered only if adequate monitoring could be applied according to the patient's condition.

\section{Economic aspects of ward-based NIV}

In most countries, healthcare has been placed in the setting of a market economy. Physicians and managers are challenged not only to find the best, but also the cheapest treatment that brings the most benefits to the individual patient without harming the hospital budget. A few pharmacoeconomic studies have addressed the cost-effectiveness of NIV [27, 52-59]. Respiratory support is a highly expensive procedure, especially when performed in an ICU. This is why a substantial reduction of medical costs was noted in all of these investigations.

Ornek et al. note that NIV itself is a huge factor that increases treatment costs for a COPD patient [58]. The study by Parker et al. found that ward-based NIV was not only equally effective to high-dependency and intensive care unit NIV, but was also more cost-effective $(p<0.05)$ [28]. European researchers from developed countries also support this finding $[56,58,59]$.

As for pre-hospital NIV, the situation does not look that promising. CPAP provided by emergency teams in ambulances could be effective in terms of mortality and intubation rate reduction, but with uncertain cost-effectiveness which depends on the prevalence of eligible patients [10,35].

Developing countries are highly dependent on the cost of any therapeutic intervention. Patel et al. compared the cost-effectiveness of ward-based NIV vs. standard therapy in hospitals without an ICU. The NIV support resulted in a slight increase in costs, but also in a significant increase in quality-adjusted lifeyears (1.67 QALY) and overall survival, which makes this strategy highly cost-effective [27].

\section{Staff and equipment requirements}

To apply NIV successfully in the ward, a wellequipped area is usually needed that should have [48]: a multidisciplinary team, that has undergone extensive training in NIV application; a guideline for NIV application; opportunity to increase or decrease the nurse:patient ratio daily according to the workload; daily rounds by a respiratory specialist; constant access to emergency medical care.

The presence of a fully equipped non-invasive ventilation cart (similar to the cardiac emergency crash cart) could be useful and could shorten the staff response time to an emergency. It is recommended that such carts should be equipped with two high flow CPAP generators, one home care ventilator, one critical care ventilator, and 4 drawers with emergency i.v. medication, aerosolized medications, oxygenation and ventilation devices [60]. 
Before introducing NIV in any medical or surgical ward, all staff involved in its application should be adequately trained. They should complete a theoretical and practical NIV course on types of ventilation, initial setup, and adjustments, as well as basic monitoring. A supervising team should be available to address any questions of the ward staff as well as emergencies. Regular visits should be scheduled and the possibility for unscheduled alerting should be understood by nurses.

NIV in the ward could be initiated not only by attending physicians, respiratory technicians, and nurses but also by medical emergency teams (MET). A MET is a hospital-based team of physicians and nurses trained in advanced life support, who respond to emergency calls following a deterioration in a patient's clinical condition [61]. The involvement of a MET in ward-based NIV for cases of COPD exacerbations and pulmonary edema could enhance the safety and efficacy of the method, as long as the physician and nurses involved are trained well enough to apply the initiated by the MET therapeutic strategy [62].

\section{CONCLUSION}

NIV is considered a fundamental method in treating patients with various disorders, requiring respiratory support. Often the lack of beds in the ICU and the concomitant medical conditions, which refer patients as unsuitable for aggressive treatment in ICU, highlight the need of NIV application in general non-monitored wards and unusual settings - most commonly emergency departments, high-dependency units, pulmonary wards, and even ambulances. Recent studies suggest faster improvement of all physiological variables, reduced intubation rates, postoperative pulmonary complications and hospital mortality with better outcome and quality of life by early wellmonitored ward-based NIV compared to standard medical therapy in patients with exacerbation of a chronic obstructive pulmonary disease, after a surgical procedure or acute hypoxemic respiratory failure in hematologic malignancies. NIV is a ceiling of treatment and a comfort measure in many patients with do-not-intubate orders due to terminal illnesses. NIV is beneficial only by proper administration with appropriate monitoring and screening for early NIV failure. Successful NIV application in a ward requires a well-equipped area and adequately trained multidisciplinary team. It could be initiated not only by attending physicians, respiratory technicians, and nurses but also by medical emergency teams. Ward-based NIV is supposed to be more cost-effective than NIV in the ICU, but further investigation is required to establish its safety and efficacy in wards with a low nurse to patient ratio.

Disclosure summary: The authors have nothing to disclose.

\section{REFERENCES:}

1. British Thoracic Society Standards of Care Committee. BTS guideline: Non-invasive ventilation in acute respiratory failure. Thorax 2002;57:192-211.

2. Rochwerg B, Brochard L, Elliott MW, et al. Official ERS/ATS clinical practice guidelines: noninvasive ventilation for acute respiratory failure. Eur Respir J. 2017;50:pii:1602426.

3. Hess DR. Noninvasive Ventilation for Neuromuscular Disease. Clin Chest Med 2018;39(2):437-47.

4. Yamakova Y, llieva VA, Petkov R, Yankov G. Nanomembrane-Based Therapeutic Plasmapheresis after Non-Invasive Ventilation Failure for Treatment of a Patient with Acute Respiratory Distress Syndrome and Myasthenia Gravis: A Case Report. Blood Purif 2019;48(4):382-4.

5. Gonzalez C, Ferris G, Diaz J et al. Kyphoscolioticventilatory insufficiency: effects of long-term intermittent positive-pressure ventilation. Chest 2003;124:857-62.

6. Duarte AG, Justino E, Bigler T, Grady J. Outcomes of morbidly obese patients requiring mechanical ventilation for acute respiratory failure. Crit Care Med 2007;35(3):732.

7. Chiumello D, Conti G, Foti G et al. Non-invasive ventilation outside the Intensive Care Unit for acute respiratory failure. Minerva Anestesiol 2009;75(7-8):459-66.

8. Cardoso LTQ, Grion CMC, Bonametti AM et al. Intensive care unit bed shortage leading to a delay in patient admission to public intensive care units. Crit Care 2007;11(Suppl 3):P94.

9. Ozsancak Ugurlu A, Sidhom SS, Khodabandeh A, et al. Where is Noninvasive Ventilation Actually Delivered for Acute Respiratory Failure? Lung 2015;193(5):779-88.

10. Pandor A, Thokala P, Goodacre S, et al. Pre-hospital noninvasive ventilation for acute respiratory failure: a systematic review and cost-effectiveness evaluation. Health Technol Assess 2015;19(42):v-vi, 1-102.

11. Wood KA, Lewis L, Von Harz B, Kollef MH. The use of noninvasive positive pressure ventilation in the emergency department: results of a randomized clinical trial. Chest 1998;113(5):1339-46.

12. Cabrini L, Esquinas $A$, Pasin $L$, et al. An international survey on noninvasive ventilation use for acute respiratory failure in general non-monitored wards. Respir Care 2015;60(4):586-92.

13. Antonelli M, Conti G, Moro ML, et al. Predictors of failure of noninvasive positive pressure ventilation in patients with acute hypoxemic respiratory failure: a multi-center study. Intensive Care Med 2001;27(11):1718-28.

14. Ilieva V, Yamakova Y, Petkov R, Yankov G. Factors of Non-invasive Ventialtion (NIV) Failure in Patients with Acute Hypoxemic Respiratory Failure due to Severe Community Acquired Pneumonia (CAP). Knowl - Int J 2018;28(2):469-77.

15. Nicolini A, Ferrera L, Santo $M$ et al. Noninvasive ventilation for hypercapnic exacerbation of chronic obstructive pulmonary disease: factors related to noninvasive ventilation failure. Pol Arch Med Wewn 2014;124(10):525-31. 
16. Lewis H, Wharton C, Agarwal S, et al. P221 Temporal Trends in Severity and In-Hospital Mortality in Acute Hypercapnic Respiratory Failure (AHRF) at a Respiratory Ward-Based NonInvasive Ventilation (NIV) Unit. Thorax 2012;67:A161-A162.

17. Dave C, Turner A, Thomas A, et al. Utility of respiratory wardbased NIV in acidotic hypercapnic respiratory failure. Respirology 2014;19(8):1241-7.

18. Schiavo A, Renis M, Polverino $M$ et al. Acid-base balance, serum electrolytes and need for non-invasive ventilation in patients with hypercapnic acute exacerbation of chronic obstructive pulmonary disease admitted to an internal medicine ward. Multidiscip Respir Med 2016;11:23.

19. Plant PK, Owen JL, Elliott MW. Early use of non-invasive ventilation for acute exacerbations of chronic obstructive pulmonary disease on general respiratory wards: a multicentre randomised controlled trial. Lancet 2000;355(9219):1931-5.

20. Dikensoy O, Ikidag B, Filiz A, Bayram N. Comparison of noninvasive ventilation and standard medical therapy in acute hypercapnic respiratory failure: a randomised controlled study at a tertiary health centre in SE Turkey. Int J Clin Pr 2002;56(2):85-8.

21. Dres M, Tran TC, Aegerter P, et al. Influence of ICU casevolume on the management and hospital outcomes of acute exacerbations of chronic obstructive pulmonary disease. Crit Care Med 2013;41(8):1884-92.

22. Fernández GJ, López-Campos BJL, Perea-Milla LE et al. Non invasive ventilation for acute exacerbation of chronic obstructive pulmonary disease: a meta-analysis. Med Clin Barc 2003;120(8):281-6.

23. Fiorino $S$, Bacchi-Reggiani L, Detotto $E$, et al. Efficacy of noninvasive mechanical ventilation in the general ward in patients with chronic obstructive pulmonary disease admitted for hypercapnic acute respiratory failure and $\mathrm{pH}<7.35$ : a feasibility pilot study. Intern Med J 2015;45(5):527-37.

24. Olivieri C, Carenzo L, Vignazia GL, et al. Does noninvasive ventilation delivery in the ward provide early effective ventilation? Respir Care 2015;60(1):6-11.

25. Trethewey SP, Edgar RG, Morlet J et al. Late presentation of acute hypercapnic respiratory failure carries a high mortality risk in COPD patients treated with ward-based NIV. Respir Med 2019;151:128-32.

26. Yalcinsoy M, Salturk C, Oztas S, et al. Can patients with moderate to severe acute respiratory failure from COPD be treated safely with noninvasive mechanical ventilation on the ward? Int J Chron Obstruct Pulmon Dis 2016;11:1151-60.

27. Patel SP, Pena ME, Babcock Cl. Cost-effectiveness of noninvasive ventilation for chronic obstructive pulmonary diseaserelated respiratory failure in Indian hospitals without ICU facilities. Lung India 2015;32:549-56.

28. Parker K, Perikala V, Aminazad A, et al. Models of care for non-invasive ventilation in the Acute COPD Comparison of three Tertiary hospitals (ACT3) study. Respirology 2018;23(5):492-7.

29. Aiken LH, Cheung RB, Olds DM. Education policy initiatives to address the nurse shortage in the United States. Health Aff Millwood 2009;28(4):w646-56.

30. Duffield CM, Roche MA, Homer $C$ et al. A comparative review of nurse turnover rates and costs across countries. J Adv Nurs 2014;70(12):2703-12.

31. Halter M, Boiko O, Pelone F, et al. The determinants and consequences of adult nursing staff turnover: a systematic review of systematic reviews. BMC Health Serv Res 2017;17(1):824.

32. Cui J, Wan Q, Wu X, et al. Nutritional Risk Screening 2002 as a Predictor of Outcome During General Ward-Based Nonin- vasive Ventilation in Chronic Obstructive Pulmonary Disease with Respiratory Failure. Med Sci Monit 2015;21:2786-93.

33. Lari F, Giostra F, Bragagni G, Di Battista N. Continuous positive airway pressure in acute pulmonary edema. application in a general medical ward. Recenti Prog Med 2011;102(3):114-9.

34. Crane SD, Elliott MW, Gilligan P et al. Randomised controlled comparison of continuous positive airways pressure, bilevel non-invasive ventilation, and standard treatment in emergency department patients with acute cardiogenic pulmonary oedema. Emerg Med J 2004;21(2):155-61.

35. Thokala P, Goodacre S, Ward M et al. Cost-effectiveness of Out-of-Hospital Continuous Positive Airway Pressure for Acute Respiratory Failure. Ann Emerg Med 2015;65(5):556-63.

36. Badiger R, Green M, Hackwood $\mathrm{H}$ et al. Non-invasive ventilation in surgical patients in a district general hospital. Anaesthesia 2004;59(10):967-70.

37. Olper L, Cabrini L, Landoni G, et al. Non-invasive ventilation after cardiac surgery outside the Intensive Care Unit. Minerva Anestesiol 2011;77(1):40-5.

38. Lockstone J, Parry SM, Denehy L, et al. Physiotherapist administered, non-invasive ventilation to reduce postoperative pulmonary complications in high-risk patients following elective upper abdominal surgery; a before-and-after cohort implementation study. Physiotherapy 2018; pii: S00319406(18):30651-5.

39. Al Jaaly E, Fiorentino F, Reeves BC, et al. Effect of adding postoperative noninvasive ventilation to usual care to prevent pulmonary complications in patients undergoing coronary artery bypass grafting: a randomized controlled trial. J Thorac Cardiovasc Surg 2013;146(4):912-8.

40. Bagan P, Bouayad M, Benabdesselam A et al. Prevention of pulmonary complications after aortic surgery: evaluation of prophylactic noninvasiveperioperative ventilation. Ann Vasc Surg 2011;25(7):920-2.

41. Barbagallo M, Ortu A, Spadini E, et al. Prophylactic use of helmet CPAP after pulmonary lobectomy: a prospective randomized controlled study. Respir Care 2012;57(9):1418-24.

42. Guangyuan L, Rongchang $\mathrm{Ch}$, Jianxing $\mathrm{H}$. Prophylactic use of noninvasive positive pressure ventilation in postthoracic surgery patients: A prospective randomized control study. J Thorac Dis 2010;2:205-9.

43. Ireland CJ, Chapman TM, Mathew SF et al. Continuous positive airway pressure (CPAP) during the postoperative period for prevention of postoperative morbidity and mortality following major abdominal surgery. Cochrane Database Syst Rev 2014;(8):CD008930.

44. Lorut C, Lefebvre A, Planquette B, et al. Early postoperative prophylactic noninvasive ventilation after major lung resection in COPD patients: a randomized controlled trial. Intensive Care Med 2014;40(2):220-7.

45. Roceto Ldos S, Galhardo FD, Saad IA, Toro IF. Continuous positive airway pressure (CPAP) after lung resection: a randomized clinical trial. Sao Paulo Med J 2014;132(1):41-7.

46. Principi T, Pantanetti S, Catani F, et al. Noninvasive continuous positive airway pressure delivered by helmet in hematological malignancy patients with hypoxemic acute respiratory failure. Intensive Care Med 2004;30(1):147-50.

47. Wilson ME, Majzoub AM, Dobler CC, et al. Noninvasive Ventilation in Patients With Do-Not-Intubate and Comfort-Measures-Only Orders: A Systematic Review and Meta-Analysis. Crit Care Med 2018;46(8):1209-16.

48. Tretheway SP, Edgar RG, Turner AM, Mukherjee R. WardBased Non-Invasive Ventilation in Acute Exacerbations of 
COPD: A Narrative Review of Current Practice and Outcomes in the UK. Healthc Basel 2018;6(4):145.

49. Ozyilmaz E, Ozsancak, Nava S. Timing of noninvasive ventilation failure: causes, risk factors, and potential remedies. BMC Pulm. Med 2014;14:19.

50. Roberts CM, Stone RA, Buckingham RJ et al. National Chronic Obstructive Pulmonary Disease Resources and Outcomes Project implementation group. Acidosis, non-invasive ventilation and mortality in hospitalised COPD exacerbations. Thorax 2011;66(1):43-8.

51. Ergan B, Nasiłowski J, Winck JC. How should we monitor patients with acute respiratory failure treated with noninvasive ventilation? Eur Respir Rev 2018;27(148):170101.

52. Bertolini G, Confalonieri M, Rossi $\mathrm{C}$ et al. Costs of the COPD. Differences between intensive care unit and respiratory intermediate care unit. Respir Med 2005;99:894-900.

53. Chandra K, Blackhouse G, Campbell M, Costa KV. Cost-effectiveness of interventions for chronic obstructive pulmonary disease (COPD) using an Ontario policy model. Ont Health Technol Assess Ser 2012;12(12):1-61.

54. Criner GJ, Kreimer DT, Tomaselli $M$ et al. Financial implications of noninvasive positive pressure ventilation (NPPV). Chest 1995; 108:475-82.

55. llieva V, Mihalova T, Yamakova Yo et al. Cost-minimization analysis of Non-invasive ventilation and Invasive mechanical ventilation for de novo acute hypoxemic respiratory failure. Acta Medica Bulg 2019;46(1):17-20.
56. Keenan SP, Gregor J, Sibbald WJ et al. Noninvasive positive pressure ventilation in the setting of severe, acute exacerbations of chronic obstructive pulmonary disease: more effective and less expensive. Crit Care Med 2000;28(6):2094-102.

57. Nava S, Evangelisti I, Rampulla $C$ et al. Human and financial costs of noninvasive mechanical ventilation in patients affected by COPD and acute respiratory failure. Chest 1997;111(6):1631-8.

58. Ornek $\mathrm{T}$, Tor $\mathrm{M}$, Altin $\mathrm{R}$, et al. Clinical factors affecting the direct cost of patients hospitalized with acute exacerbation of chronic obstructive pulmonary disease. Int J Med Sci 2012;9(4):285-90.

59. Plant PK, Owen JL, Parrott S, Elliot MW. Cost effectiveness of ward based non-invasive ventilation for acute exacerbations of chronic obstructive pulmonary disease: economic analysis of randomised controlled trial. Br Med J 2003;326(7396):956.

60. Lari F, Bortolotti R, Scandellari N, et al. The development of a bedside cart for the management of acute respiratory failure with non-invasive ventilation in Internal Medicine wards. Recenti Prog Med 2013;104(3):93-7.

61. Barbetti J, Lee G. Medical emergency team: a review of the literature. Nurs Crit Care 2008;13(2):80-5.

62. Khalid I, Sherbini N, Qushmaq I, et al. Outcomes of patients treated with noninvasive ventilation by a medical emergency team on the wards. Respir Care 2014;59(2):186-92.

Received: 05 March 2020, Accepted: 05 August 2020 